\title{
Performance Analysis of Ad hoc Routing Protocols for Voice Communication Support over Hybrid MANETs
}

\author{
Rajneesh Kumar Gujral \\ Assoc. Professor \\ Computer Engineering \\ Department, \\ M. M. Engineering College, \\ M. M. University, \\ Ambala, India-133207
}

\author{
Manpreet Singh \\ Professor \\ Computer Engineering \\ Department, \\ M. M. Engineering College, \\ M. M. University, \\ Ambala, India-133207
}

\begin{abstract}
Multimedia real-time session services, such as voice and videoconferencing with Quality of Service support is challenging task on Mobile Ad hoc Network (MANETS). For providing multimedia services and Voice over Internet Protocol in MANET, support for Session Initiation Protocol ( SIP) is essential .The goal of QoS provisioning is to achieve a more deterministic network behaviors, so that information carried by the network can be better delivered and network resources can be better utilized. In this paper, we have analyzed various QoS parameters on different routing protocols for the voice transmission using OPNET simulator. The performance metrics comprises of QoS parameters such as packet delivery ratio, end to end delay, packet delay variation, routing overhead, throughput and jitter.
\end{abstract}

Keywords: QoS, VoIP, MANETs etc.

\section{INTRODUCTION}

MANET is a collection of wireless mobile nodes which dynamically forms a temporary network without the use of any existing network infrastructure or centralized administration. MANET possess different features in the form of dynamic topologies, bandwidth-constrained, variable capacity links, energy constrained operation and limited physical security. The increase in multimedia, military application traffic has led to extensive research focused on achieving QoS guarantees in current networks. The QoS parameters differ from application to application e.g., in case of multimedia application bandwidth, jitter and delay are the key QoS parameters [1].Two major trends in technology can be observed over the last decade: pervasive communication and the Internet. Pervasive communication is slowly but surely becoming an integral part of our daily life. The Internet has also become a central aspect for almost everybody, both in business, at home or during education. It is thus essential for us to bridge those two technologies, where future wireless communication systems are expected to provide a broad range of multimedia services. MANETs are reaching a stage where they can support these services in order to provide an infrastructure useful for the common user. Thus, the interconnection of MANETs to fixed infrastructure based IP networks is very important in order to provide the ubiquitous user access internet anywhere at any time [2], [3]. In such scenarios, also known as "Internet connected MANET", or "hybrid MANET", the user within an Ad hoc network will get access to the public internet by using the packet forwarding capabilities of intermediate Ad hoc network nodes towards the Access Router (AR) or gateway to the Internet, providing the user with access to different services through a diversity of interconnected networks (fixed, wireless and Ad hoc networks). To offer advanced services, such as multimedia communication for hybrid MANETs, the support of Voice over IP (VoIP) is required. Ad Hoc On-Demand Distance Vector (AODV), and Dynamic Source Routing protocol (DSR), Optimized Link State Routing protocol (OLSR) (proactive) and temporarily Ordered Routing Algorithm (TORA) are the key protocols that have been considered for the investigation. IN this paper figure 1, illustrates two different MANETs which are connected through internet to form a Hybrid MANET and they can make voice calls to each other using VoIP application.

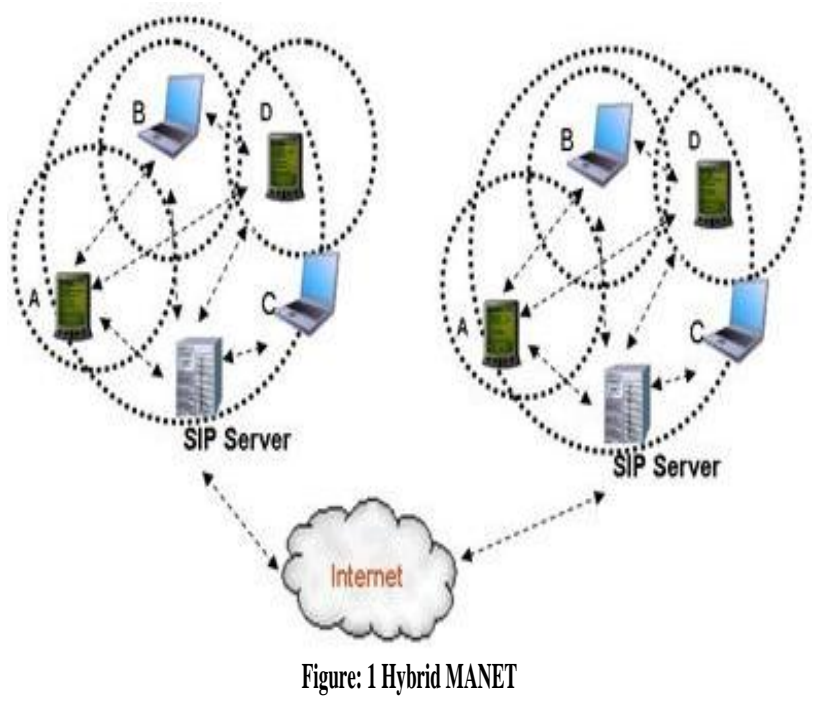


The rest of paper is organized as follow. Section 2, deals with related work, Section 3, gives an overview of routing protocols, performance metrics in section 4 , Section 5 simulation results and analysis are discussed and section 6 concludes the paper.

\section{RELATED WORK}

The performance of different reactive routing protocols, such as the Ad Hoc On Demand Distance Vector (AODV), Dynamic Source Routing (DSR) and Temporally-Ordered Routing Algorithm (TORA), with variation in load of real-time traffic is evaluated in [4]. These routing protocols have high transmission delay as they determine the routing table only if there is traffic in the network. In [5], the performance of VoIP systems in an Ad hoc network with stationery nodes using two routing protocols: Ad hoc on-demand distance vector (AODV) and Optimized Link State Routing (OLSR) is analyzed. In [6] the deployment of VoIP services with the AODV routing protocol and analysis of different performances metrics, such as jitter, one-way delay, frequency of service interruptions and their duration is made. An integrated SIP-based session establishment mechanism with extensions of the DSR over MANET through effectively applying the cross-layer design between the networking routing protocol and the application layer SIP method is proposed in [7]. In [8], a novel service discovery mechanism for supporting SIP-based multimedia session services over a proactively routed MANET is proposed. Performance evaluation results reveal that the distributed proxyless architecture is more robust as it is not constrained by the location and capacity of the proxy server, and may thus deliver relatively better session application performance, e.g., higher throughput and lower setup latency. The limitations of SIP service scalability when centralized proxies/registrars located in the Access Networks are used by MANET nodes is analyzed [9]. In [10] performance of Signaling Compression (SigComp) to reduce session setup delay with different compression algorithms in Mobile Ad hoc Networks (MANETs) taking account The related work does not give any information about MANET routing protocol which can offer better the voice transmission .In this paper, we have analyzed the performance of some routing protocols (AODV, DSR, OLSR and TORA) during voice transmission in term of certain QoS parameters.

\section{DESCRIPTION OF THE PROTOCOLS}

\subsection{Ad hoc On Demand Distance Vector} (AODV)

AODV routing protocol is also based upon distance vector, and uses destination numbers to determine the freshness of routes. It operates in the on demand fashion, as opposed to the proactive way of the DSDV protocol. AODV is capable of both unicast and multicast routing [11]. AODV requires hosts to maintain only active routes. An active route is a route used to forward at least one packet within the past active timeout period. When a host needs to reach to destination and does not have an active route, it broadcasts a route request (RREQ), which is flooded in the network. A route can be determined when RREQ is received either by the destination itself or by an intermediate host with an active route to that destination. A route reply (RREP) is unicast back to the originator of RREQ to establish the route. Each host that receives RREQ caches a route back to the originator of the request, so that RREP can be sent back. Every route expires after a predetermined period of time. Sending a packet via a route will reset the associated expiry time. It uses HELLO message to determine the connectivity among the neighbours. Features of this protocols include lop-freedom and that link breakage cause immediate notification to be sent to the affected set of nodes.

\subsection{Dynamic Source Routing (DSR)}

DSR is a multi-hop routing protocol proposed for MANETs [11]. It is based on the concept of source routing in contrast to hop-by-hop routing. It includes two mechanisms, route discovery and route maintenance. Route discovery is the process by which a source node discovers a route to a destination for which it dos not already have a route in its cache. The process broadcasts a RREQ packet that is flooded across the network in a controlled manner. In addition to the address of the original initiator of the request and the target of the request, each RREQ packet contains a roué record, which records the sequence of hops taken by the RREQ packet as it propagates through the network. RREQ packets use sequence numbers to prevent duplication. The request is answered by a RREP packet either from the destination or an intermediate node that has a cached route to the destination. DSR uses aggressive caching to reduce the frequency and propagation of route discoveries. The original design of DSR [12] uses a path cache which stores whole source routes. Another design, called a link cache proposed in [13], stores individual links of routes to build a topological graph of the network. The route maintenance procedure monitors the operation of the route and informs the sender of any routing errors. If a route breaks due to a link failure, the detecting host sends a RRER packet to the source which upon receiving it, removes all routes in the host's cache that use the hop in error.

\subsection{Temporally ordered routing algorithm}

TORA [14] is a source-initiated on-demand routing protocol which uses a link reversal algorithm and provides loop-free multipath routes to a destination node. In TORA, each node maintains its one-hop local topology information and also has the capability to detect partitions. TORA incurs less control overhead and the local reconfiguration of paths results in nonoptimal routes. The distance metric used in TORA which is nothing but the length of the path, or the height from the destination. $\mathrm{H}(\mathrm{N})$ denotes the height of node $\mathrm{N}$ from the destination. TORA has three main functions: establishing, maintaining, and erasing routes. The route establishment function is performed only when a node requires a path to a destination but does not have any directed link. This process establishes a destination-oriented directed acyclic graph (DAG) 
using a query/update mechanism. TORA incurs less control overhead and the local reconfiguration of paths results in nonoptimal routes.

\subsection{Optimized Link State Routing}

OLSR [15] is a proactive routing protocol for MANETs. OLSR is an optimization over the classical link state protocol, tailored for MANETs. OLSR minimizes the overhead from flooding of control traffic by using only selected nodes, called MPRs, to retransmit control messages. This technique significantly reduces the number of retransmissions required to flood a message to all nodes in the network. Secondly, OLSR requires only partial link state to be flooded in order to provide shortest path routes. The minimal set of link state information required is, that all nodes, selected as MPRs, must declare the links to their MPR selectors. OLSR may optimize the reactivity to topological changes by reducing the maximum time interval for periodic control message transmission. Furthermore, as OLSR continuously maintains routes to all destinations in the network, the protocol is beneficial for traffic patterns where a large subset of nodes are communicating with another large subset of nodes, and where the [source, destination] pairs are changing over time. The protocol is particularly suited for large and dense networks, as the optimization done using MPRs works well in this context. The larger and more dense a network, the more optimization can be achieved as compared to the classic link state algorithm.

\subsection{Session Initiation Protocol}

SIP is an application layer control protocol used for establishing, modifying and tearing down multimedia sessions, both unicast and multicast. It has been standardized within the IETF for the invitation to multicast conferences and Internet telephone calls [16].The most important SIP operation is that of inviting new participants to a call. To achieve this functionality we can distinguish different SIP entities:

Proxy server: A proxy server receives a request and then forwards it towards the current location of the callee either directly to the callee or to another server that might be better informed about the actual location of the callee.

Redirect server: A redirect server receives a request and informs the caller about the next hop server. The caller then contacts the next hop server directly.

User Agent (UA): A logical entity in the terminal equipment that can act as both a User Agent Client (UAC) and a User Agent Server (UAS).

Registrar: The register server is mainly thought to be a database containing locations as well as user preferences as indicated by the user agents.

In detail, a SIP call setup is essentially a 3-way handshake between a caller (UAC) and a callee (UAS). For instance, the main legs are an INVITE (to initiate a call) message, a 200 OK (to communicate a definitive successful response) message and an ACK (to acknowledge the response) message. However, implementations can make use of provisional responses, such as
180 RINGING message. 180 RINGING message indicates that the callee (UAS) receiving the INVITE message is trying to alert the user. The call setup is followed by the actual media transfer (speech and video) using the Real-time Transport Protocol (RTP) [17]. The release of the call is made by means of the BYE; message and the successful call release can be communicated through a $200 \mathrm{OK}$ message.

\section{PERFORMANCE ANALYSIS}

The performance of Routing protocols during transmission of Voice is simulated using OPNET simulator. Figure 2(a-d) shows the simulation parameters and configuration of Routing Protocol, Proxy Server, SIP Client, Voice Encoding and Voice Table Configuration on each Nodes is depicted in figure 3(a-e) .

\subsection{Performance Metrics}

The performance metrics includes the following QoS parameters such as PDR (Packet Delivery Ratio), Throughput, End to End Delay, Routing overhead and Jitter.

Packet Delivery Ratio: The fraction of packets sent by the application that are received by the receivers. End-to-end delay: indicates how long it took for a packet to travel from the source to the application layer of the destination. Jitter: Jitter is the variation in the time between packets arriving, caused by network congestion, timing drift, or route changes.

Throughput: The throughput is defined as the total amount of data a receiver receives from the sender divided by the time it takes for the receiver to get the last packet. Routing Load: Routing Load is the ratio of total number of the routing packets to the total number of received data packets at destination.

Packet Delay Variation: Difference in "end-to-end delay" between selected packets in a flow is called Packet Delay Variation.

\section{SIMULATION RESULTS AND ANALYSIS}

The parameters used for simulation and different scenario on which they are analyzed are shown in Table 1 and Table 2 respectively. The Hybrid MANET consist of 16 different hybrid devices in the form of PDA and laptop to participate in voice communication along with a SIP proxy server configured to provide SIP proxy services to the SIP clients (mobile nodes) as shown in figure 4 .

Table 1: Simulation Parameters

\begin{tabular}{|l|c|}
\hline Parameters & Value \\
\hline Simulation Time & $600 \mathrm{sec}$ \\
\hline Number of nodes & 16 \\
\hline Ad hoc Network & 02 \\
\hline Proxy Server & 01 \\
\hline Router/Access Point & 01 Node(8) \\
\hline Internet Connection & 2 \\
\hline Ad Hoc Protocols & AODV,DSR.TORA,OLSR \\
\hline
\end{tabular}




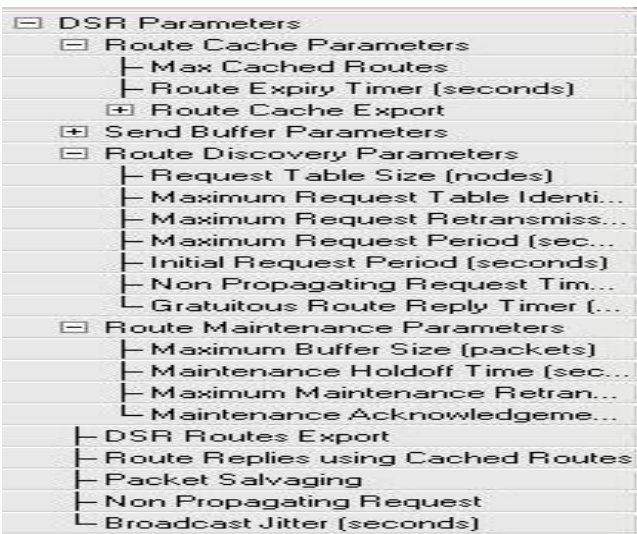

[...]

[nfinit

300

Do Nat Export

[...]

[...

64

16

16

10

0.5

0.03

(...)

50

0.25

2

2.5

Do Nat Export

Enabled

Enabled

Disabled

(a)

\section{- OLSR Parameters}

FWillingness

- Hello Interval [seconds]

- TC Interval [seconds]

- Neighbor Hold Time [seconds]

- Topology Hold Time [seconds]

- Duplicate Message Hold Time [se.

LAddressing Mode
[...]

Willingness Default

2.0

5. 0

6.0

15.0

30.0

IP 4

(b)

\begin{tabular}{|c|c|c|}
\hline (?) & -AD-HOC Routing Protocol & AODV \\
\hline (3) & - AODV Parameters & (..) \\
\hline (?) & + Poute Discoveru Parameters & $(\ldots)$ \\
\hline (?) & F-Active Route Timeout [seconds] & 3 \\
\hline (3) & - Hello Interval (seconds) & uniform $[1,1.1]$ \\
\hline (3) & -Allowed Hello Loss & 2 \\
\hline (3) & - Net Diameter & 35 \\
\hline (?) & - Node Traversal Time [seconds] & 0.04 \\
\hline (?) & - Route Error Rate Limit (pkts/sec) & 10 \\
\hline (3) & - Timeout Buffer & 2 \\
\hline
\end{tabular}

(c)

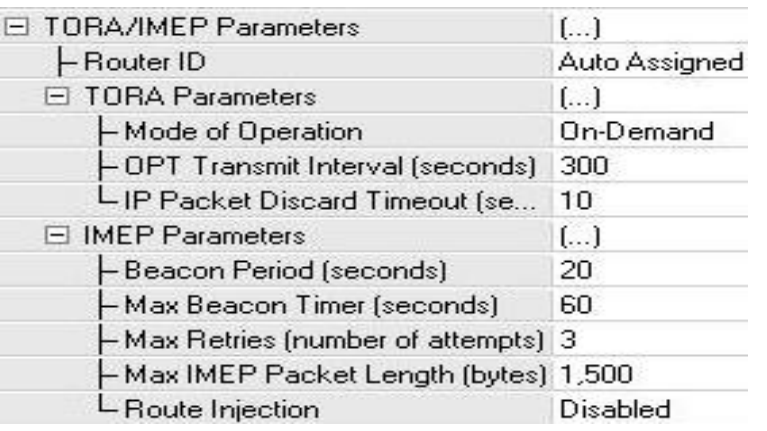

(d)

Figure 2 (a-d) Parameters setting for routing protocols

$\begin{array}{llll}\text { AD.HOC Routing Protocol } & \text {-Name } & \text { G.711 (silence) } \\ \text { AODV Parameters } & \text { NODV } & \text {-Frame Size [secs) } & 4 \mathrm{msec} \\ \text { DSR Parameters } & \text { None } & \text {-Lookahead Size (secs) } & 0 \mathrm{msec} \\ \text { OLSR Parameters } & \text { SODV } & \text {-DSP Processing Ratio } & 1.0 \\ \text { TORA/MEP Parameters } & \text { OLSR } & \text { - Coding Rate (bits/sec) } & 64 \mathrm{Kbps} \\ & \text { TORA } & \text { L-Speech Activity Detection } & \text { Enabled }\end{array}$

(a)

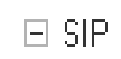

(?) -Server Address

(b)

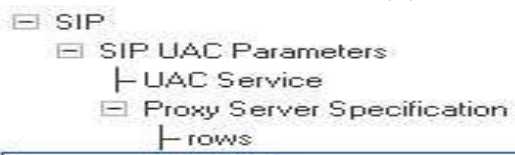

$(\ldots)$

Enabled

Unlimited

1.1.1.1

[...

Enabled

[...

1

1.1.1.1

Unlimited

TCP Based

(d)

\begin{tabular}{|c|c|c|}
\hline (Woice) Table & & $x$ \\
\hline Attribute & Value & -1 \\
\hline Silence Length (seconds] & default & \\
\hline Talk Spurt Length [seconds] & default & \\
\hline Symbolic Destination Name & Voice Destination & \\
\hline Encoder Scheme & G.711 (silence) & \\
\hline Voice Frames per Packet & 1 & \\
\hline Type of Service & Interactive Voice $[6]$ & \\
\hline RSVP Parameters & None & \\
\hline Traffic Mix $[\%]$ & All Discrete & \\
\hline Signaling & SIP & \\
\hline Compression Delay [seconds] & 0.02 & \\
\hline Decompression Delay (seconds) & 0.02 & $=1$ \\
\hline Promote & Cancel & \\
\hline
\end{tabular}

(e)

Figure 3 (a-e) Configured Routing Protocol, Proxy Server, SIP Client, Voice Encoding and Voice Table Configuration on each Nodes 


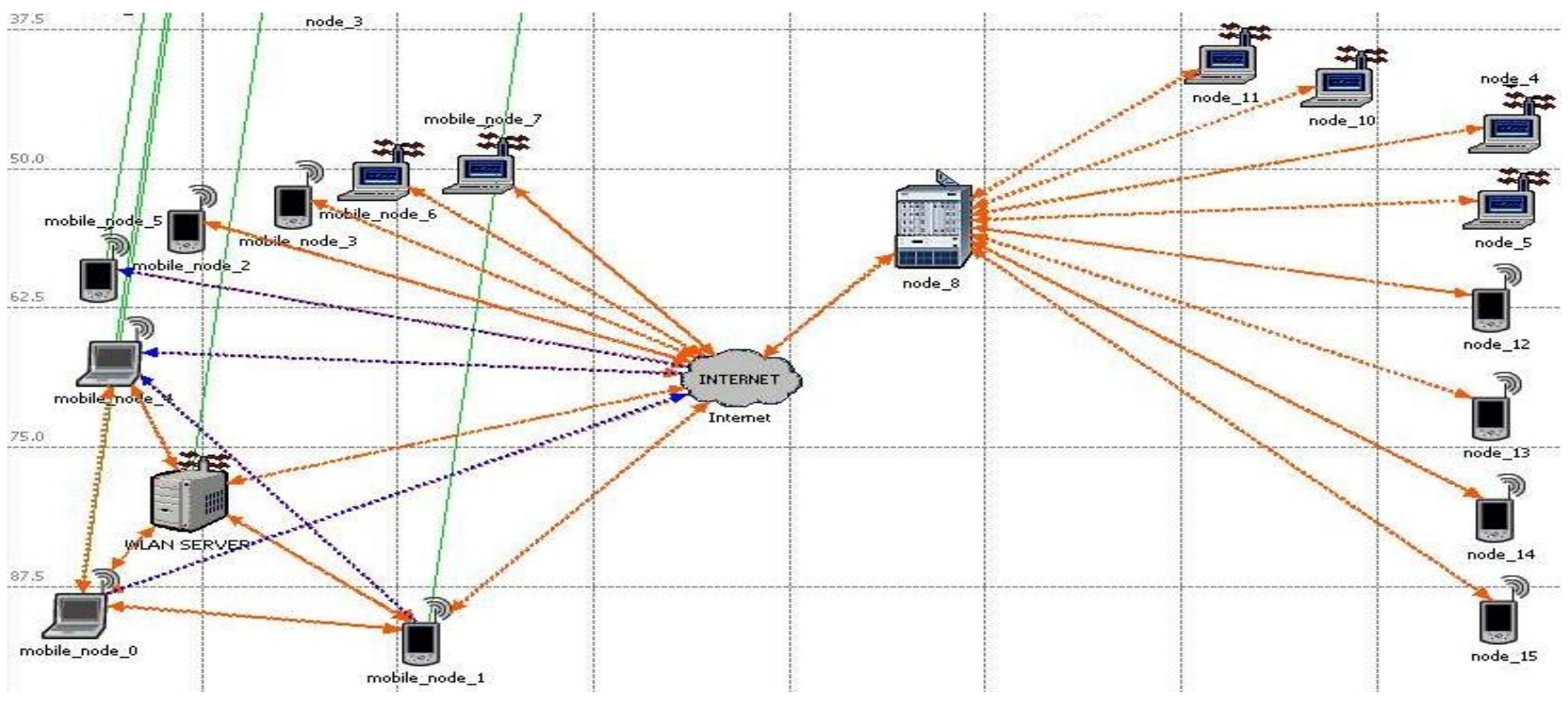

Figure 4 Scenario for Hybrid MANET for the voice communication

Table 2: List of Scenarios Used in Simulation

\begin{tabular}{|l|l|}
\hline Scenario Name & Ad Hoc Protocol Used \\
\hline Scenario1_AODV & AODV \\
\hline Scenario2_DSR & DSR \\
\hline Scenario3_OLSR & OLSR \\
\hline Scenario4_TORA & TORA \\
\hline
\end{tabular}

For simulation, we have configured the mobile devices to support the different protocols and then generated the VoIP traffic. The mobile devices have been categorized in two different groups: Calling node and Called node as indicated in figure 5 and table 3 .

Voice Application: It is installed on each node to support voice communication.

Voice Calling Node: It makes a call to called node. Voice Called Node: It receives a call made by calling node

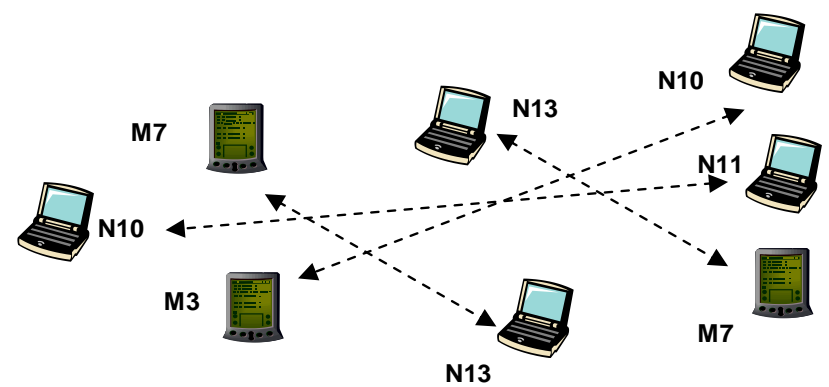

Figure 5 Calling and Called nodes in MANET

Table 3: Voice Communication Setup

\begin{tabular}{|l|l|}
\hline Calling node & Called node \\
\hline $\mathrm{M}-3$ & $\mathrm{~N} 1$ \\
\hline $\mathrm{M}-7$ & $\mathrm{~N}-13$ \\
\hline $\mathrm{N}-10$ & $\mathrm{~N}-11$ \\
\hline
\end{tabular}

The Figure 6 and 7 illustrates that the SIP active calls are increased over the time and SIP Clients (mobile nodes) are making requests to start the voice communication to the SIP proxy Server .Table 4 shows the Call Setup Time, Active Calls, Voice Traffic Sent and Voice Traffic Received over different Routing Protocols.

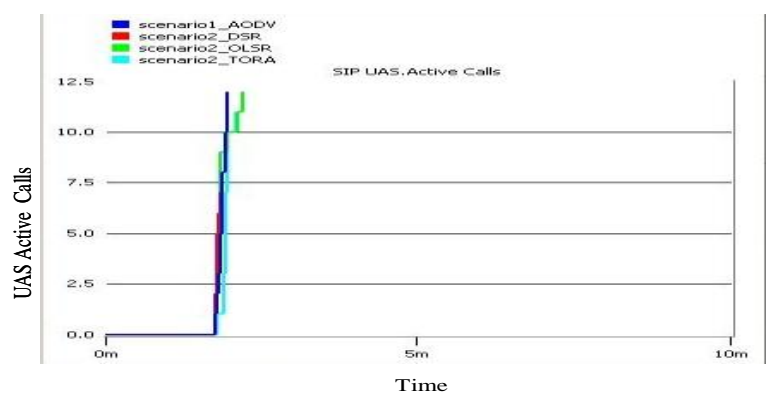

Figure 6 Shows that SIP Active Calls which are increased over the time.

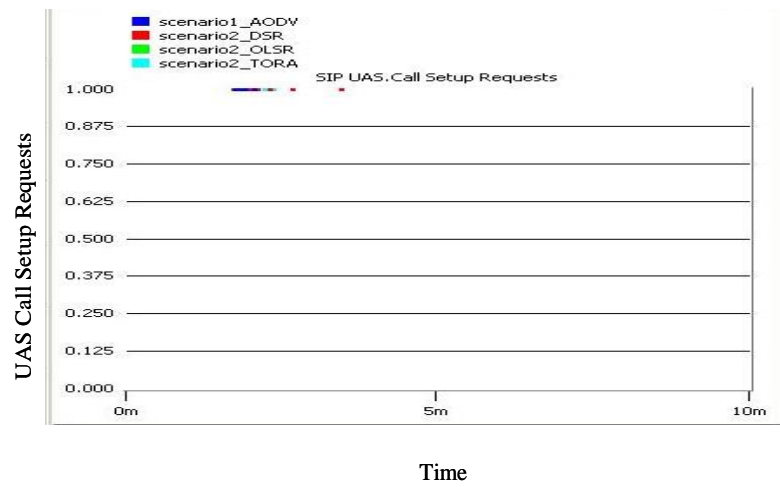

Figure 7 shows that SIP Clients (mobile nods) are making requests to start the voice communication to the SIP proxy Server. 
Table 4 Shows the Call Setup Time, Active Calls, Voice Traffic Sent and Voice Traffic Received.

\begin{tabular}{|l|c|l|c|c|}
\hline Protocols & $\begin{array}{l}\text { SIP UAS Call Setup } \\
\text { Requests }\end{array}$ & $\begin{array}{c}\text { SIP UAS } \\
\text { Active Calls }\end{array}$ & $\begin{array}{c}\text { Voice Traffic } \\
\text { Sent (Packets) }\end{array}$ & $\begin{array}{c}\text { Voice Traffic } \\
\text { Received (Packets) }\end{array}$ \\
\hline AODV & 24 & 78 & 70566.17 & 30987.5 \\
\hline DSR & 19 & 28 & 42342.17 & 7669.667 \\
\hline OLSR & 24 & 78 & 71252.33 & 32923.83 \\
\hline TORA & 23 & 66 & 34434.67 & 14482.5 \\
\hline
\end{tabular}

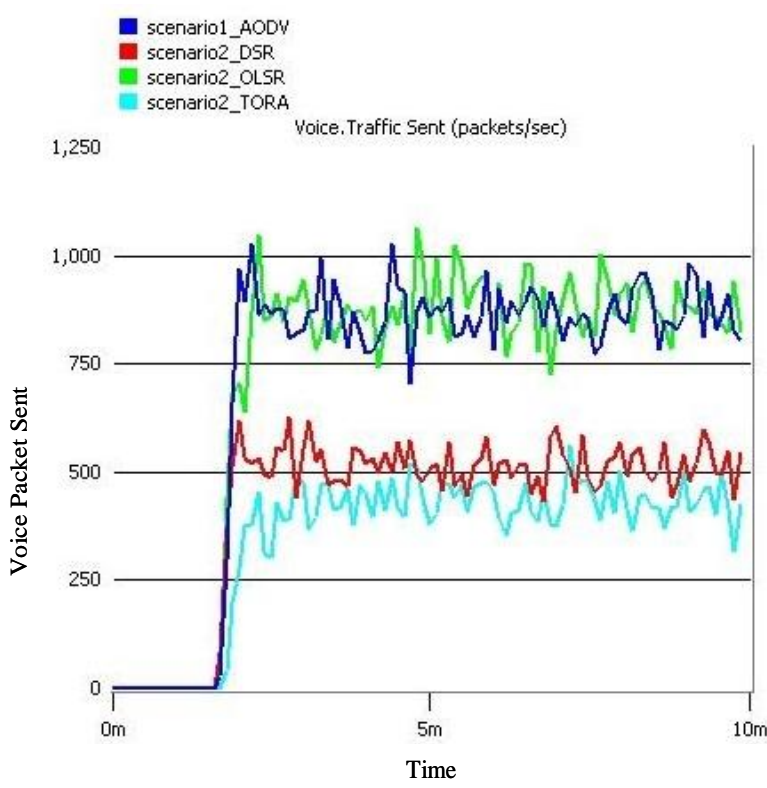

Figure 8 Voice Traffic Sent

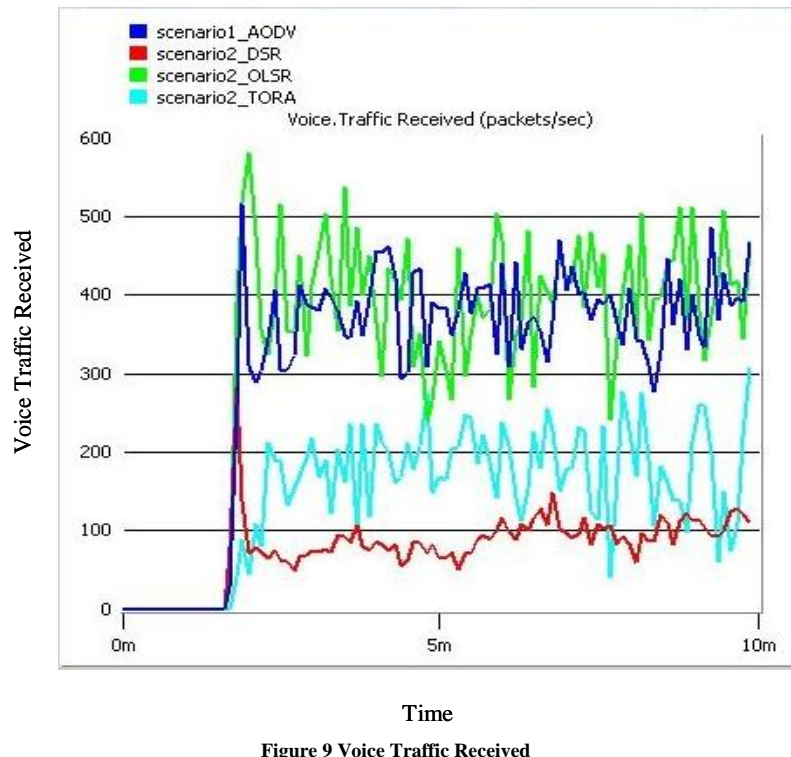

Figure 8 and 9 illustrates that the number of packets sent and received in OLSR and AODV are maximum and are lower side in TORA and DSR.

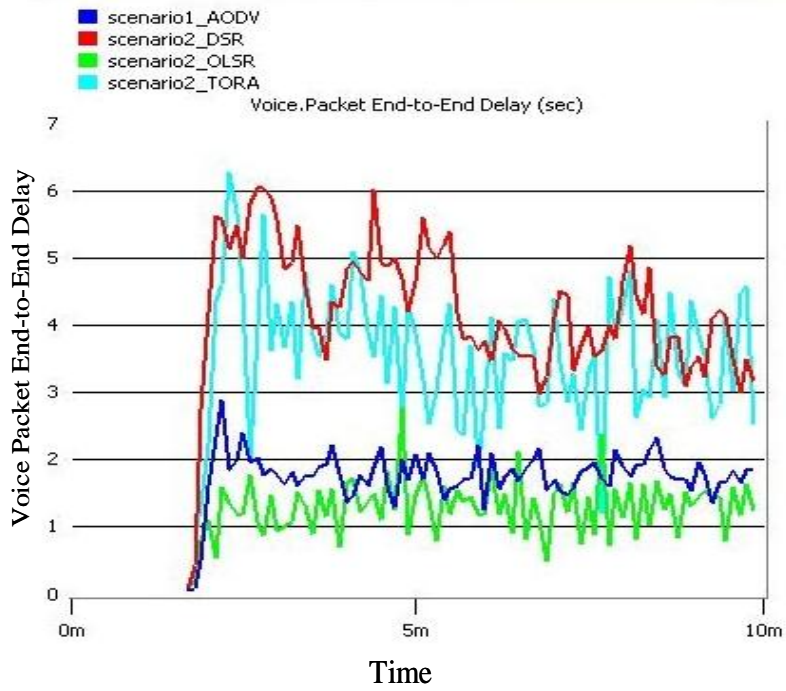

Figure 10 Voice Packet End-to-End Delay

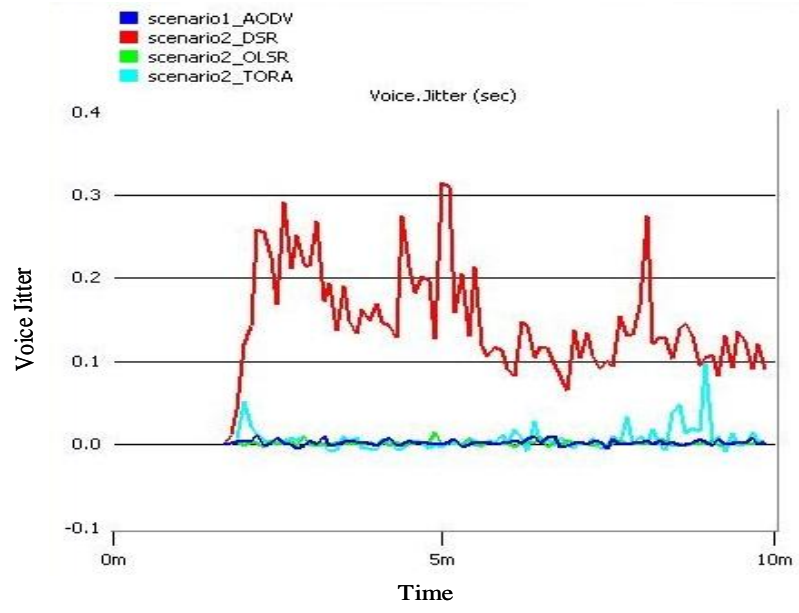

Figure 11 Shows Voice Jitter

The end-to-end delay in OLSR and AODV is lower side and is maximum in TORA and DSR as shown in figure 10. Figure 11 illustrates the comparative results in which maximum jitter is produced in DSR and TORA and is lower side in case of OLSR and AODV.

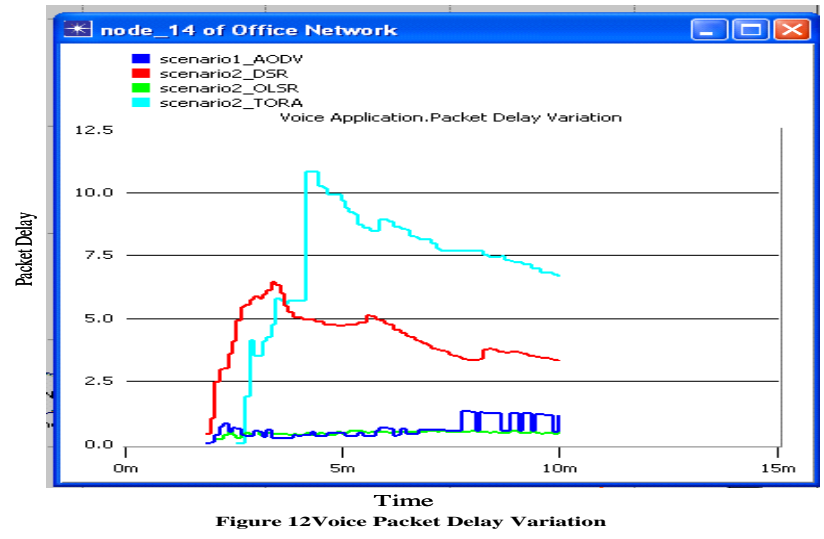

The Packet Delay Variation in TORA and DSR is maximum as 
compared to other protocols and in case of OLSR and AODV it is minimum as depicted in figure 12. Tables 5 summarize the performance of different routing protocols under various QoS parameters.

Table: 5 Performance analysis of different Routing protocols

\begin{tabular}{|l|l|l|l|l|l|l|}
\hline Protocols & Throughput & $\begin{array}{l}\text { Packet } \\
\text { Delivery } \\
\text { Ratio }\end{array}$ & $\begin{array}{l}\text { Routing } \\
\text { Load }\end{array}$ & $\begin{array}{l}\text { End-to- } \\
\text { end- } \\
\text { delay }\end{array}$ & Jitter & $\begin{array}{l}\text { Packet } \\
\text { Delay } \\
\text { Variation }\end{array}$ \\
\hline AODV & 52.16 & 43.91 & 3.27 & 145.64 & 0.21 & 95.097 \\
\hline DSR & 12.91 & 18.11 & 6.52 & 349.82 & 12.3 & 412.21 \\
\hline OLSR & 55.42 & 46.20 & 3.16 & 106.83 & 0.13 & 34.69 \\
\hline TORA & 24.38 & 42.05 & 3.37 & 294.06 & 0.55 & 629.62 \\
\hline
\end{tabular}

\section{CONCLUSION AND FUTURE SCOPE}

Finally, we have concluded that it is possible to launch voice transmission with acceptable quality and throughput over Hybrid MANETs. The overall performance of OLSR is best as all QoS parameters has favourable results as indicated in Table 5.The performance of TORA protocol is less than OLSR and AODV protocol but it is better than performance of DSR protocol. DSR protocol has minimum throughput and maximum end-to-end-delay with highest jitter and all these factors make this protocol unsuitable for voice transmission. As per analysis, we can conclude that OLSR protocol is best performer as compared to all other protocols and DSR protocol is the worst performer. In future this work can be extended to provide the support Video Conferencing, Real time remote surveillance system and MANET based Battlefield Communication System.

\section{REFERENCES}

[1] Mr. Rajneesh Gujral, Dr. Anil Kapil "Secure QoS Enabled On-Demand Link-State Multipath Routing in MANETS" Proceeding of BAIP 2010, pp. 250-257 SPRINGER LNCSCCIS, Trivandrum, Kerala, India, March 26-27, 2010.

[2] M. C. Castro, M .A. Siqueria, F.L. Figueriredo, J.A. Martins, J.H. Souza, A.L.Pacifico, L. Santos, "An Ad Hoc Wireless System for Small Towns and Rural Areas " In : Journal of Brazilian Telecommunications Society, 2005.

[3] J. Rosenberg et al.: "SIP: Session Initiation Protocol” ,RFC 3261,June 2002. www.ietf.org.

[4] K. S. Lee, S. J. Lee, and Y. K. Chung, "A Performance Comparison of On-Demand Routing Protocols for Application Data Mobile Ad hoc Networks," SERA, pp. 331- 339, 2005.
[5] S. Armenia, L. Galluccio, and A. Leonardi, S. Palazzo, "Transmission of VoIP Traffic in Multihop Ad Hoc IEEE 802.11b Networks: Experimental Results," WICON, pp. $148-155,2005$.

[6] E. Thibodeau, M. Youssef, and A. C. Houle, "Investigating MANET performance in a VoIP context," IEEE CCECE/CCGEI, pp 920 - 923 May 2006.

[7] Li Li and Louise Lamont "Support of Multimedia SIP Applications in Mobile Ad hoc Network: Service Discovery and Networking Architecture" IEEE GLOBECOM,pp no. 3682-3286 2005.

[8] Xiaoyan Zhang, Xiaofeng Du, Zygmunt Haas, "Performance Evaluation of Sip-Based Session Establishment Over DSR-Routed Manets," milcom, pp.1-7, MILCOM- 2006, 2006.

[9] Marcel C. Castro and Andreas J. KasslerOptimizing "SIP service provisioning in internet connected MANETs" Proceedings of International Symposium on QoS in Wireless Multimedia Networks, Split, Croatia, September 2006.

[10] Yanling Wu,Yuncheng Liu and Ming Li "Performance Evaluation of SigComp in MANETs"Proceddings of International Conference Multimedia Information Networking and Security (MINES) pp. 119-122,2010.

[11] Charles E. Perkins and Flizabeth M. Royer, " Ad Hoc OnDemand Distance Vector Routing," Proceeding of the $2^{\text {nd }}$ IEEE Workshopon Mobile Computing Systems and Applications,pp. 90-100,Feburuary 1999.

[12] David B. Johnson, David A. Maltz, Yih-Chun Hu, "The Dynamic Source Routing Protocol for Mobile Ad Hoc Networks (DSR)", draft-ietf-manet-dsr-10.txt, july 2004.

[13] Y.-C.Hu and D.B.Johnson "Caching Strategies in ondemand routing protocols for wireless ad hoc networks" Proceeding of ACM MobiCom, August 2000.

[14] V. Park and S. Corson "Temporally-Ordered Routing Algorithm (TORA) Version 1Functional Specification" draft-ietf-manet-tora-spec-04.txt, July 2001.

[15] T. H. Clausen and P. Jacquet "Optimized Link State Routing Protocol, Evaluation Through Experiments and Simulation," RFC -3636, October 2003.

[16] J. Rosenberg, H. Schulzrinne, G. Camarillo "session initiation protocol” RFC-3261, june 2002.

[17] T. Clausen, "Comparative Study of Routing Protocols for Mobile Ad hoc Networks", INRIA Research Report, N.5135, Mar 2004. 